\title{
Speech Acts and Discourse Pattern in Information Sharing Practice in Malaysian Web-Forums
}

\author{
Shanthi, A., Thayalan, X, and Suppiah, P
}

Universiti Teknologi MARA, Shah Alam, Malaysia

\section{Abstract}

Web-forum discussions are widely used in business, health and education and in general discussion virtually. This practice of sharing information via Internet is also known as Computer Mediated Discourse (CMD). By focusing on language used in web-forums, this study explores the practice of collaborative information sharing in Malaysian web-forums discourse by using Speech Acts Theory. The study found that forum-members used different speech acts to share information in an interactive manner. However, speech acts such as to explain, to suggest and to question were used more extensively than other types of speech acts. The study also found that

Corresponding Author:

Shanthi, A.

aliceshanthi@uitm.edu.my

Received: 1 July 2019

Accepted: 18 July 2019

Published: 31 July 2019

Publishing services provided by

Knowledge E

(c) Shanthi, A. et al. This article is distributed under the terms of the Creative Commons

Attribution License, which permits unrestricted use and redistribution provided that the original author and source are credited.

Selection and Peer-review unde the responsibility of the AICLL 2019 Conference Committee. speech acts to denote politeness such as to apologise, to greet were used in the web-forum interaction to sustain collaboration and camaraderie in online information sharing practices. The discourse pattern reveals that web-forum members interacted at two phrases; Phase 1 to seek general information about the topic of discussion, and Phase II to have a deeper discussion where new information is added to the topic of discussion that leads to new knowledge being created. The findings of the study can benefit our understandings on how best to conduct online interaction, be it in the business, health or academic sectors.

Keywords: Web-forum, Computer-Mediated Communication, Language Forms and Functions, Information Sharing

\section{Introduction}

Increasingly, it has been noted that Computer-mediated Discourse (CMD) via modes such as blogs, discussion forums or web-forums, wikis, emails and instant messaging have become an inexpensive way to collaborate, to exchange information and to seek answers to problems among members of a virtual community. In CMD information sharing practice can be understood as "a set of activities by which information is provided to others, either proactively or upon request, such that the information can impact people's view or knowledge of the world" (Savolaine, 2015). Discussions using the Internet can either be synchronous or asynchronous. Discussion via web forums is categorized as asynchronous, because it does not require the reader to reply instantaneously to 
messages but rather it allows forum members to check other resources for information and contemplate on it before sharing it online. Thus, web forums become a place where forum members bring resources, knowledge and expertise so that collectively they could help one another to share information and gain better insight on the topic of discussion (Shanthi, Thayalan, \& Xavierine, 2018)

One of the reasons why sharing information via Internet has become popular is because there is no real purpose for people to meet face-to-face to "talk" about an issues or problem when Internet allows people from different demographic characteristic to gather virtually to discuss any issues especially over issues of common interest. Also, because problems faced by people today are often multi-faceted and require group rather than individual solutions (loannou, Brown, \& Artino, 2015), Therefore, webforums serve as communication hubs for people who work together to solve particular problems (Gritsenko, 2016).

According to Wood and Kroger (2000), when studying the role of language in communication, "Language must be seen as action", however this action is more complicated when carried out online because in computer-mediated communication (CMC) facial cues and other nonverbal communication cues like tone of voice are not available. Therefore, when web-forum members are engaged mutually in a common endeavour to share information, miscommunications may occur and disrupt the flow of information. Hence, a good information sharing environment will encourage a continuous flow of thought sharing, and this in return would ensure the continuity and maintain members in any online group (Shanthi et al., 2018). When disruptions happen repeatedly in webforum interaction, forum members may get discouraged which affect information shared online (Shanthi, 2017). The reason for claiming that web-forum interaction is a viable information sharing platform is that in good information sharing practice, initial ideas are reshaped and become new information as web-forum members dig deeper into the topic of discussion (Shanthi et al., 2018). Additionally, the process of reshaping ideas that become new information is constructed through social interaction and collaboration with others (Vygotsky, 1978; Holstein \& Gubrium, 2013; Mihail, Rubin, \& Goldsmith, 2014).

While sharing information in online platforms such as web-forums, speech acts play an important role because while communicating forum members make certain language choices known as speech acts. Speech Acts Theory by Austin (1975) stresses that people do not only use a language to assert things, but also to do things. Speech act is commonly defined as a pre-supposed action that a speaker would want the hearer to do after listening to a speaker (Maros \& Halim, 2018). 
Thus, it is important to understand how language used in online communities function to increase interactions among forum members. In this study the researchers examine the language choices made by the writers of the messages by using speech act. This step will explain the functions the messages seem to carry. Together these language functions will form a discourse pattern that represents web-forum interaction where information is actively shared. In short, the focus of this study is to find a common pattern of collaborative information sharing in web-forums by focusing on the speech acts used to seek and share information in a computer-mediated discourse (CMD)in a web-forum. Hence, the aim of the study is (1) to identify speech acts that were used to collaboratively share information in web-forum, and (2) to identify the discourse pattern of web-forum information sharing practice.

\section{Literature Review}

To understand a social phenomenon such as web-forum interaction, language is the only means to make sense of the meaning that is shaping in CMD. The main assumption is that language does not passively label objects but actively shapes and moulds reality (Frowe, 2001). In short, people use language for a reason such as to ask for information and to make suggestions. Therefore, language is a mode of action that adds meaning to the conversation (Searle, 1981). In order to analyse the action that a language performs, Speech Act Theory is used. Speech Act Theory is based on J.L. Austin's How to Do Things with Words, first introduced in 1962. The major premise of this theory is that - language is a mode of action that adds meaning to the conversation. Therefore, speech acts are the building blocks for a meaningful discourse. Speech Acts Theory is used widely in research to understand how individuals construct meaning while communicating with another person either at a personal level or as a group. According to (Austin, 1962), speech acts refers to acts of communication that are used to express a certain attitude, and the type of speech act being executed corresponds to the type of attitude being expressed. Therefore, in this study, the theory of speech acts is used to explain how the act of sharing information is carried out in web-forums.

In this study web-forums are selected because they allow people to read and exchange comments and views on subjects or issues that they are commonly interested in. Discussion forums is one of the most common types of asynchronous Computer Mediated Communication (CMC) which enables multiple users to engage in discussion with one another; read and exchange comments beyond real time (Shanthi, Thayalan, Xavierine, \& Hamuddin, 2017). Thus, it is a good tool for generating dialogue among 
users and to solicit feedback from others (Molinillo, Aguilar-Illescas, Anaya-Sánchez, \& Vallespín-Arán, 2018; Moreillon, 2015; Shanthi, 2017). It also allows for information to be stored in chronological order so that the flow of information is easily retrieved, and not lost in the frantic exchange of information as in synchronous online chatting. In web-forum interactions the content, context, timing, and structure of interaction are automatically recorded, providing rich group interaction data for researchers (Gritsenko, 2016). Also, in web-forum interactions, new members can join the web-forum discussion at any point of the interaction after reading the previous postings to share his or her thoughts. As such, in web-forums effective information sharing strategies becomes integral to both parties; the writer and the reader who keep switching roles in order to seek and share information. Their relationship must be in harmony with one another be it in the manner they communicate or the quality of information shared (Shanthi et al., 2018). Also, in the process of commenting on the views of others and sharing their own thoughts, forum members contribute to the reshaping of ideas that becomes new information (Lu, Lin, Hsiao, \& Cheng, 2010).

Web-forums are also selected for this study because they are commonly used in the academic, health and business settings where members come to share information among them. In short, web-forums become increasing popular because they create a safe and easy-to-use, and easy to access online environment where community members offer help and support directly or through anonymity (Thayalan \& Mohd Noor, 2010).

\section{Research Method}

The primary data source for this study is the naturally occurring text-based asynchronous interactions generated from Lowyat.net; a popular web-forum provider in Malaysia that discussed Malaysian themed topics. Table 1 shows the seven web-forums that are selected for the study. The data collected from the web-forum discussions are unstructured, where any forum member could initiate a discussion (thread starter) or contribute to discussions initiated by others (ordinary forum member).

Data selection is guided by Herring's Computer Mediated Discourse Analysis (CMDA) framework. CMDA is an approach to researching computer mediated discourse that applies methods adapted from language-focused disciplines such as linguistics, communication, and rhetoric (Herring \& Androutsopoulos, 2015). Analysis of the data involve coding and tagging for speech acts based on the action that the messages appear to 
perform in the web-forum interaction and it is not based on any prescribed coding system. Therefore, data interpretation is based solely on evidence gathered on language use in the web-forums interaction.

TABLE 1: Forum Titles and their coding initials.

\begin{tabular}{|l|l|}
\hline Web-Forum Titles & Initials \\
\hline F1-Proton Saga FLX Very High Fuel Consumption & SAGA \\
\hline F2-JPA, LAN, MOHE and how to differentiate good UnirCol & UNI \\
\hline F3-GST reducos business cost-potentially final price & CST \\
\hline F4-Starting a little oun business. & BUS \\
\hline F5- Working for PETRONAS V2 & PETR0 \\
\hline F6-CukbaiPintu explained & CUKAI \\
\hline F7- Insurance TalkV2 & INS \\
\hline
\end{tabular}

Over the course of three months' observation, seven web-forums were selected from a pool of web-forums covering various groups of interest. The data consisted of over 1767 messages that amounted to slightly over four million words. The naturally occurring data from the web-forums selected were captured using NCapture to collect PDF documents displayed in the web browser and then imported into the researchers' NVivo project to be coded according to the speech acts they seem to perform. The analytical procedure of data analysis is depicted in Figure 1.

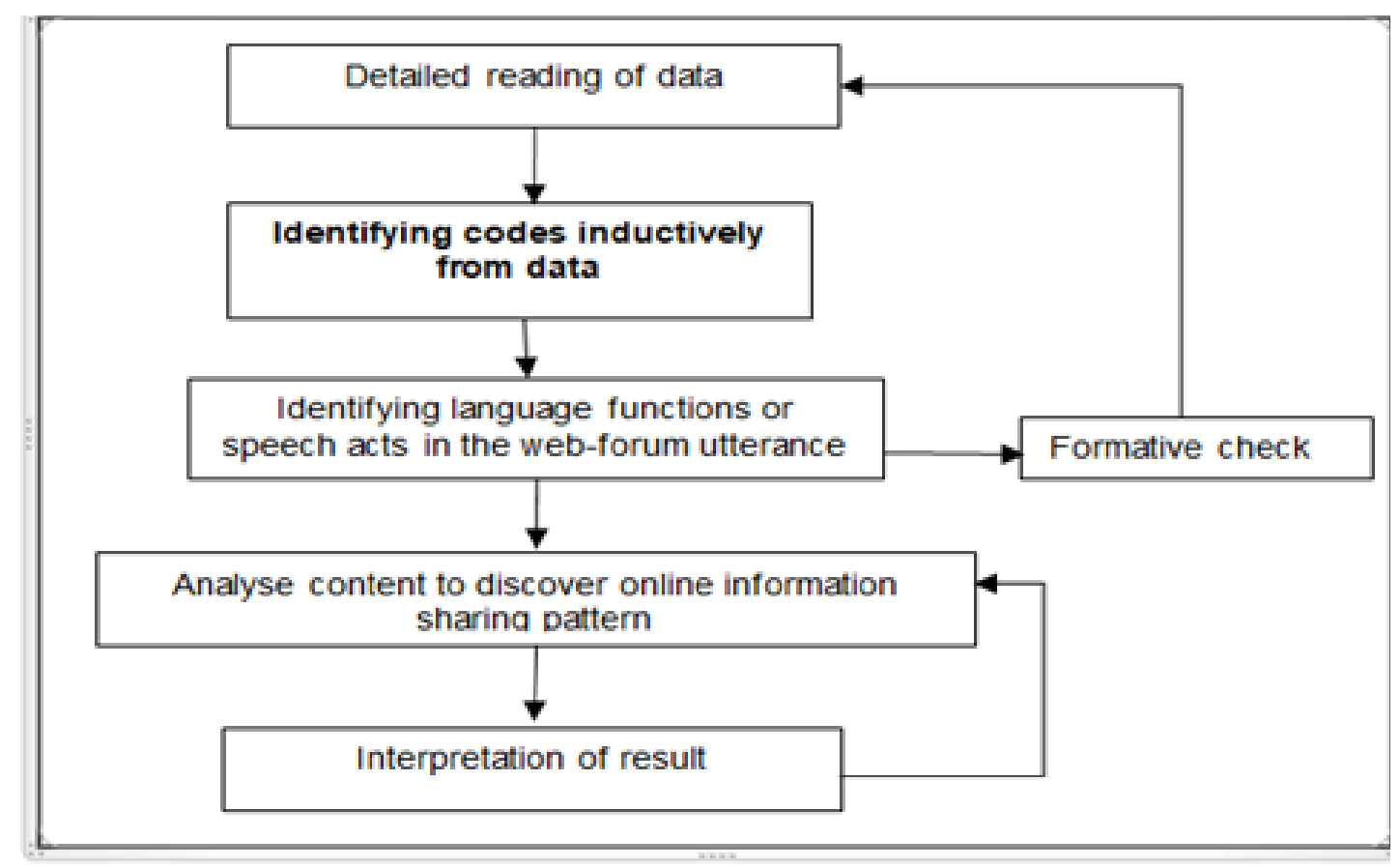

Figure 1: Analytical Procedure of Data Analysis. 
As seen in Figure 1, the initial analytical process started after reading the data. All the researchers read through the web-forums to tag the speech acts with a list of speech act categories and their descriptions. In particular, they evaluate and come to an agreement on a given set of speech act categories. The ten most used speech acts that came from the reading and tagging of the web-forum is listed in Table 2.

TABLE 2: Speech Act Descriptors.

Speech Act
1. explaining (elaborate answer)
2. simple answer
3. questioning
4. disapproving
5.being respectful/polite
6. suggesting
7. requesting
8. complimenting
9. acknowledging
10 defending

Description
An answer requiring a full description/reasons
Answer with short phrases or words (Yes/No)
Question on specific problem
Criticizing, correcting or objecting
Greetings/ leave-taking/thanking
Give suggestions /advices for a problem
Asking for answers for a problem
Praise an argument or suggestion
Confirm or acknowledging
Justifying one's stand/argument/opinion

During the tagging and coding process each utterance is classified according to speech act categories such as question, elaboration, correction, answer, request as seen in the following example (the speech acts are given in parentheses $<>$ ):

Example 1:

$\mathrm{Hi},<$ polite-greeting $>$ is there any $\mathrm{AIA}$ agent here? $<$ question $>$ Yesterday $\mathrm{AIA}$ telemarketer called me, and introduce me a PA plan 'Premiere PA' <explain>. Any idea what is that $<$ request $>$ ? Couldn't find related info in website. Thanks, $<$ polite-leave taking $>$ ! (F7INS\#16blue_scott)

Next, as seen in Figure 1, within a feedback loop the categories are revised and checked. After going through the speech act analysis that answered the question on which speech acts are widely used for web-forum interaction. The next issue to address is to capture the discourse pattern of the web-forum interaction. The webforum discourse pattern is identified by tagging the messages posted in the webforum according to the function they seem to perform; seeking information, providing information, discussing an issue, refuting claim, and/or social behaviour of sustaining group harmony.

1. seeking information (question, request)

2. providing information (answer/suggestion/correction)

3. agreeing (acknowledge) 
4. disagreeing (objecting, defending)

5. social behaviour of sustaining group harmony (greeting, thanking, joking, reprimanding)

\section{Result and Discussion}

For the purpose of reporting, no changes were made to the messages like correcting the spelling or grammar errors. The following codes are used to present data in the analysis:

1. F1 - F7 $=$ Web-forum number, titles and their initials as shown in Table 1.

2. \# = Web-forum posting number (e.g. \#350)

3. Followed by the pseudonyms of the web-forum members used to register as users in the Lowyat.net.

For example, the code F7INS\#350duckverse refers to forum number 7 (Insurance Talk V2) as seen in Table 1 and is coded with the initials INS, posting number 350 by web-forum member who carried the pseudonym duckverse.

Close reading and tagging of the seven asynchronous web-forums for speech acts revealed that there were ten speech acts that were actively used for sharing information in the web-forums interaction as shown in Table 3.

TABLE 3: Speech Acts Used for Collaborative Sharing of Information in Web-forums

\begin{tabular}{|l|c|c|}
\hline Language Function & Count & Frequency (\%) \\
\hline 1. explaining & 879 & 20.71 \\
\hline 2. suggesting & 476 & 11.22 \\
\hline 3. questioning & 455 & 10.72 \\
\hline 4. disapproving & 409 & 9.64 \\
\hline 5.being respectful/polite & 385 & 9.07 \\
\hline 6.simple answer & 359 & 8.46 \\
\hline 7. requesting & 281 & 6.62 \\
\hline 8. complimenting & 216 & 5.09 \\
\hline 9. acknowledging & 115 & 2.71 \\
\hline 10. defending & 100 & 2.36 \\
\hline
\end{tabular}

As seen in Table 3, ten speech acts were identified as having a higher frequency of occurrence compared to others in the web-forum interaction. In addition, among the first ten speech acts listed in Table 1, the speech act to explain (20.71\%) has the 
highest frequency count, almost twice the number of speech act to suggest (11.22\%) and to question (10.72\%). This is mainly because the speech act to explain is used both by the members (the tread-starters) who came to the web-forum to explain their problems/issues and ordinary forum members who explained in detail to forum members who posted a query.

Example 2 shows how web-forum members use the speech act to explain, to suggest, and to questions in the excerpt taken from a web-forum that was discussing on the local cars manufactured in Malaysia.

\section{Example 2}

have problem with my Saga FLX $1.3 \mathrm{CVT}$,.....for a full tank of petrol $\mathrm{i}$ can only drive around $240 \mathrm{~km}$ which is not normal when comparing to other people, they can clock roughly $300 \mathrm{~km}$ something or more. <explain >

Can you guys give me any opinion or solutions to rectify my problem? requesting>

(F1SAGA\#1soffianzainal)

a) you switch to other petrol brand first and see how it goes <suggesting>. Your service is still long due.

(F1SAGA\#23Kompressor)

b) what brand you recommend me to

use? requesting?.

(F1SAGA\#24soffianzainal)

c) esso or caltex or BHP «suggesting>. but I personally pump Esso since there's smiles driver rewards program <simple nswers.

(F1SAGA\#25Kompressor)

d) u can try anything, just dn't try shell <suggest >

(F1SAGA\#27MR_alien)

e) so shell 95 fuel is bad? <questioning>

(F1SAGA\#29soffianzainal)

In Example 2, thread starter (TS) Soffianzainal gave the background information to the problem he was facing, next he posted a request to other forum members requesting for their feedback that might help TS to solve his problem. Member Kompressor and $M R \_a l i e n$ came in to give suggestions, answers and plausible explanation (Example 1a, 1c, and 1d) to help and enlighten the TS. However, when the given feedback did not have enough information forum members asked questions to seek further clarification (Example 1b, 1e).

The analysis of the data in the study also found that forum members often disapproved the views given by other members by criticising, correcting or objecting to the views of other $(9.64 \%)$. When issues were raised it was common for forum members to disapprove, and used different ways to express disapproval. This act of disapproval can be done casually using phrases such as / disagree, or by using stronger words that depict criticism. This study found that forum members used almost the same percentage of disapproving language functions (9.64\%) and language functions that denote being respectful (9.07\%). This goes to prove that as much as forum members argued and used disapproving speech acts, they carried out the disapproving speech act by being 
respectful (being polite) to each other like apologizing first before correcting others. This is depicted in Examples 3 and 4.

\section{Example 3}

Sorry optiplex330<disapproving - respectfully>, look at all the numbers above, and explanation from both coolsarawak and martianunlimited ${ }^{\text {supporting>. }}$. Also i suggest you look at both of their maths, and understand the basics of it, because your simplistic view of $6 \%$ GST is lower than $16 \%$ SST is amusing ${ }^{\text {disapproving-> }}$. Yes we know 6 is lower than 16. But if we think like you, then you are just saying that the government is gonna lose $10 \%$ of it's tax revenue because it wants to <defending> (F1GST\#57sasivarman)

Human communication tells us that people generally do not like to be corrected harshly, but most might take it if it is done in a diplomatic way (DeVito, 2012). As shown in Example 3, forum member sasivarman from F3-GST reduces business cost -potentially final price- does not use harsh words to disapprove of forum member Optiplex330's views, instead s/he used phrases such as <Sorry optiplex 330>before pointing out the flaws in member Optiplex330 views. Sasivarman also claims support by quoting other forum members (coolsarawak and martianunlimited) who were in-line with member sasivarman's views as a way to say that $s /$ he is not alone in disagreeing with Optiplex330, therefore Optiplex330 should be able to accept the correction pointed out by sasivarman.

\section{Example 4}

a) Thanks for enlighten me on this matters ${ }^{<\text {thanking }>}$...

This is why i posted in lowyat forum is because i need this kind of advice

to avoid failure <complimenting>

(F4BUS\#41Kelvin5717)

b) $\mathrm{Hi}$ <being respectful -greeting>, don't mind me asking <being respectful-

hedging $>$. Is it legal fees and stamp duty based on house value or loan value? <question>

(F6CUKAI\#194aobk84)

Example 4 shows web-forum members are being respectful to the others who have helped to share information that was useful to them who had joined the virtual interaction seeking information. In Example 4a, forum member Ke/vin5717 thanked and complimented the forum members in his/her thread who s/he claims had given good advice and suggestion to avoid failure in opening a small food business. In Example $4 \mathrm{~b}$, member aobk84 can be construed as being respectful of other forum members, firstly by greeting them, then veiling his/her question by hedging so as not to sound imposing before actually asking the question.

The findings of the study show that the language functions to explain, to suggest, to question, to disapprove, to be respectful, to reply or answer, to compliment, to acknowledge and to defend are mostly used in web-forum interaction to share information in 
web-forums. These language functions enabled forum members to support, reinforce and debate on each other's ideas and opinions so as to lead the topic of discussion into a more in-depth discussion. Hence, it is noteworthy that altogether these ten language functions occurred 3675 times or $87 \%$ (Table 2) from the total number of speech acts identified in the analysis of data in this study.

The data recorded 1789 messages that were coded according to the discourse function they seem to perform. As seen Table 3 from the 1789 messages, 1767 represented almost $99 \%$ of the main five discourse functions identified from the data. Another 22 messages were coded for some lesser used discourse function such as fillers that did not directly contribute any useful information to the topic of discussion but rather used as a delaying tactic used to sustain discourse. The five main discourse functions are:

1. seeking information

2. providing information

3. agreeing with information shared

4. disagreeing with information shared

5. sustain group harmony

As seen in Table 3, this study found that the forum-members mainly came to the web-forums to share information (43.1\%) while $16.7 \%$ of forum members came to ask for information. Altogether these two discourse functions totalled-up to $59.8 \%$ of the sum of discourse functions identified from the data. Every request for information is met with messages asking for more detail of the issues faced by the thread-starter, and in the process fellow forum members start providing answers to the request raised. The discourse function of seeking and providing Information normally involve exchanges of questions, giving suggestions or advice, and/or explanations. These exchanges helped the process of co-construction of new information that forum-members sought after. By using mainly these speech acts, forum members asked for clarification, elaboration or explanation. Thus, when forum members collaborate with each other for the purpose of information seeking, it allows forum-members to pull together resources which could be based on knowledge, skill and/or first-hand experience from other members that can become new information to other web-forum members.

The study also revealed that forum-members were seen to hold a cooperative attitude so that the group harmony is sustained (16.1\%). This study found that the forum members acknowledged (14.4\%) other forum members for providing answers to their 
TABLE 4: Distribution of Discourse Function in Web-forums.

\begin{tabular}{|c|c|c|c|}
\hline $\begin{array}{l}\text { Discourse } \\
\text { function }\end{array}$ & Frequency (n) & $\begin{array}{l}\text { Percentage } \\
\text { (\%) }\end{array}$ & Example \\
\hline $\begin{array}{l}\text { Seeking } \\
\text { information }\end{array}$ & 299 & 16.7 & $\begin{array}{l}\text { Hi guys, I have a question related to MLTA. As far } \\
\text { as I know, it is essentially a life insurance that } \\
\text { designed to pay off your debt for property (and } \\
\text { perhaps some cash too). However, .....Please } \\
\text { enlighten me. } \quad \text { (F7INS\#115wiind) }\end{array}$ \\
\hline $\begin{array}{l}\text { Providing } \\
\text { information }\end{array}$ & 770 & 43.1 & $\begin{array}{l}\text { Hi wiind, I have to tell you the whole picture of } \\
\text { MLTA including MRTA so that you will understand } \\
\text { the reason why people will say MLTA is } \\
\text { "transferable" and how it "linked" to your } \\
\text { property........(went on to explain using another } \\
600-650 \text { words) (F7INS\#116ExpZero) }\end{array}$ \\
\hline Refuting claims & 152 & 8.5 & $\begin{array}{l}\text { sorry for this question... } 1 \text { if we pay cukaipintu to } \\
\text { maintain road...then y are we paying roadtax for..? } \\
2 \text { last time indah water doest exist...and it is } \\
\text { included in the cukaipintu... but y now we gota pay } \\
\text { separately? } \quad \text { (F6CUKAl\#187maximus6887) }\end{array}$ \\
\hline $\begin{array}{l}\text { Acknowledging } \\
\text { claims }\end{array}$ & 258 & 14.4 & $\begin{array}{l}\text { Thank you very much for your reply! This is } \\
\text { definitely much clearer than most explanations I } \\
\text { could find on the internet! Not only that you answer } \\
\text { my question clearly and precisely, ......... I really } \\
\text { appreciate this and I shall literally note this down } \\
\text { for future reference! (F7INS\#117wiind) }\end{array}$ \\
\hline $\begin{array}{l}\text { Sustain group } \\
\text { harmony }\end{array}$ & 288 & 16.1 & $\begin{array}{l}\text { Thanks for fact checking my calculation and having } \\
\text { no issues with it (not calling me a macai and } \\
\text { kangkung cool too) (F3GST\#222coolsarawak) }\end{array}$ \\
\hline Total & 1767 & $98.8 \%$ & \\
\hline
\end{tabular}

queries by agreeing, thanking, or greeting. For example, the language function to greet and to thank which were used to denote the coming together and taking leave of forum members were found to be essential for the establishment and maintenance of online interpersonal relationship. The forum members seem to word their messages to maintain a climate of harmony so that the experience of sharing and seeking information online can be fruitful. When members refute claims (8.5\%), they regulated their language behaviour so as not to hurt the feelings of others as seen in the third example given in Table 3. These language functions regulated cordial web-forum interaction.

\subsection{Online Discourse Pattern}

The study found that forum-members in Malaysia used different speech acts to achieve four different communicative discourse functions which all pointed to the purpose of seeking, sharing and exchanging information. The discourse pattern is portrayed in Figure 2. 


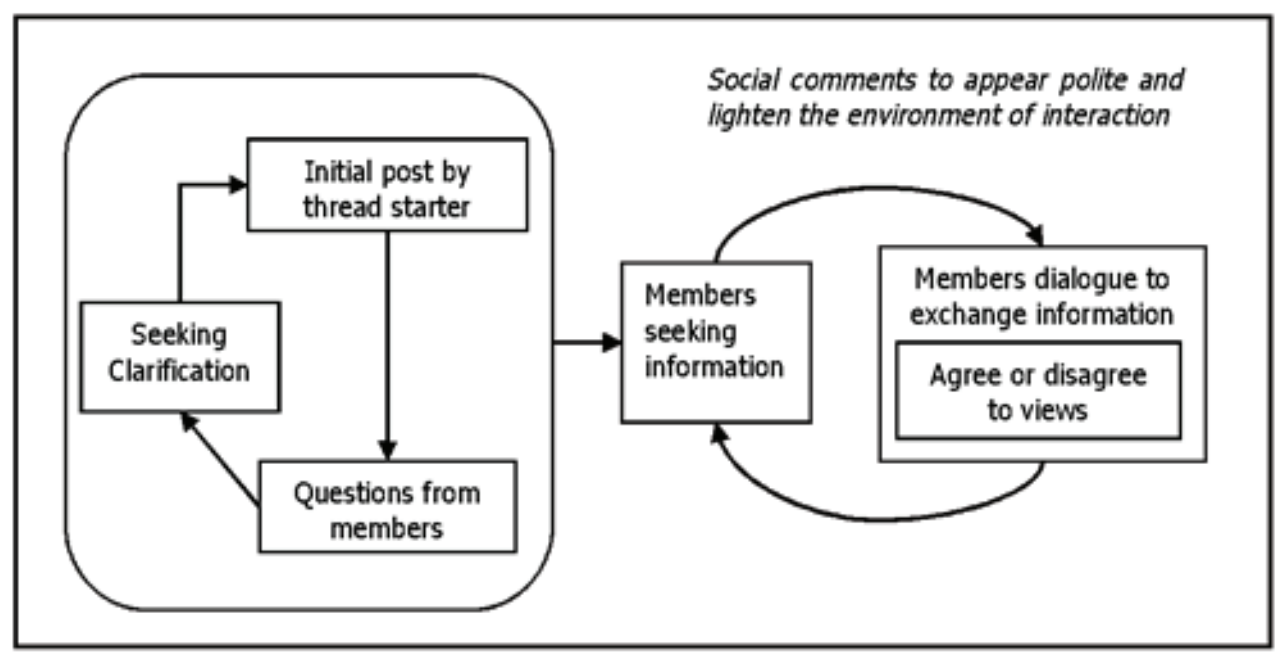

Figure 2: Discourse Pattern in Web-forum.

As seen in Figure 3, the web-forum interaction is divided into two phases. Phase I involves seeking information by forum members after the thread-starter had put forward a request asking for views and opinion on an issue. Next, they move on to Phase II of the discussion where after having sought the relevant information from Phase I. In Phase II forum members have a "dialogue" to share and exchange information, and in the process of discussion forum members agree or disagree with the views posted by other forum members based on their experiences, expertise and/or knowledge. Further in the process of dialogue when forum members agree or disagree, they explain each other's stand and might ask follow-up question before they conclude the discussion by giving suggestions or advice.

Finally, when forum-members seem to have received a favourable answer to their queries, the discussion usually shifts to another area or angle. Hence, the closing of that particular area of discussion does not signal the end of the web-forum interaction because other forum-members come up with another set of queries pertaining to the same topic of discussion, but from a different angle or perspective, thus expanding the depth of discussion within the topic of discussion. Therefore, in online information sharing practices the formation of a mutually beneficial relation is essential to ensure the information sharing process in web-forum is successful.

\section{Conclusion}

This study reports on the discourse functions found in web-forums centred in Malaysia on how they use different language functions to seek, share and exchange information in 
web-forums. By using these discourse functions, they sought, provided, acknowledged, and refuted ideas to share information in a collaborative manner. Even though at times some web-forum members display a non-cooperative attitude, yet as an online community, other forum members will either advise or criticize them so that forum members will regulate their language so as not to upset the flow of thoughts in the web-forum discussion. Overall this study found that forum members usually come into a web-forum for a reason which is either to seek or share information by using different language functions but mainly the speech acts to achieve their communicative purposes.

\section{References}

[1] Austin, J. L. (1962). How To Do Things. Cambridge UK: Oxford University Press.

[2] Frowe, I. (2001). Language and Educational Research. Journal of Philosophy of Education,35(2), 175-186.

[3] Gritsenko, V. (2016). Interaction on online forums and group communication: a case study of an IT support community. In Procedia - Social and Behavioral Sciences, 14-24. Elsevier Ltd.

[4] Herring, S. C., \& Androutsopoulos, J. (2015). Computer-Mediated Discourse 2.0. In D. Tannen, H. E. Hamilton, \& D. Schiffrin (Eds.), The Handbook of Discourse Analysis, 2 (2nd ed., pp. 127-167). John Wiley \& Sons, Inc.

[5] Holstein, J. A., \& Gubrium, J. F. (2013). The Conctructionist Analytics of Interpretive practice. In N. Denzin \& Y. Lincoln (Eds.), Strategies of Qualitative Inquiry (4th ed., pp. 253-289). Sage Publications Inc.

[6] loannou, A., Brown, S. W., \& Artino, A. R. (2015). Wikis and forums for collaborative problem-based activity: A systematic comparison of learners' interactions. Internet and Higher Education, 24, 35-45.

[7] Lu, H. P., Lin, J. C. C., Hsiao, K. L., \& Cheng, L. T. (2010). Information sharing behaviour on blogs in Taiwan: Effects of interactivities and gender differences. Journal of Information Science, 36(3), 401-416.

[8] Maros, M., \& Halim, N. S. (2018). Alerters in Malay and english speech act of request: A contrastive pragmatics analysis. 3L: Language, Linguistics, Literature, 24(1), 69-83.

[9] Mihail, R. P., Rubin, B., \& Goldsmith, J. (2014). Online Discussions区: Improving Education in CS®? In SIGCSE '14 Proceedings of the 45th ACM technical symposium on Computer science education (pp. 409-414). New York: ACM New York, NY, USA. 
[10] Molinillo, S., Aguilar-Illescas, R., Anaya-Sánchez, R., \& Vallespín-Arán, M. (2018). Exploring the impacts of interactions, social presence and emotional engagement on active collaborative learning in a social web-based environment. Computers and Education, 123(April), 41-52.

[11] Savolaine, R. (2015). Expressing emotions in information sharing_ a study of online discussion about immigration. Information Reserach an Iternational Electronic Journal, 20(1).

[12] Searle, J. (1981). Expression and Meaning: Studies in the Theory of Speech Acts (2nd ed.). New York: Cambridge University Press.

[13] Shanthi, A. (2017). Interactivity and Online Guanxi in Web-Forums in Malaysia. Universiti Malaysia Sabah.

[14] Shanthi, A., Thayalan, X., \& Xavierine, J. (2018). Features of Trust in Online Guanxi among Malaysian Web-Forum Members Features of Trust in Online Guanxi among Malaysian Web- Forum Members. IOP Conference Series: Earth and Environmental Science, 175(1).

[15] Shanthi, A., Thayalan, X., Xavierine, J., \& Hamuddin, B. (2017). Speech Acts And Phrases Of Knowledge Construction In Asynchoronous Discourse. Journal of Academia, 5, 158-165.

[16] Vygotsky, L. (1978). Mind in society. Cambridge UK: Harvard University Press.

[17] Wood, L., \& Kroger, R. (2000). Doing Discourse Analysis (1st ed.). California: Sage Publications Inc. 